\title{
The Acceptability of HPV Vaccines and Perceptions of Vaccination against HPV among Physicians and Nurses in Hong Kong
}

\author{
Teris Cheung ${ }^{1}{ }^{1}$, Joseph T.F. Lau ${ }^{2}$, Johnson Z. Wang ${ }^{2,3}$, Phoenix Mo $^{2}$, C.K. Siu ${ }^{1}$, \\ Rex T.H. Chan ${ }^{1}$ and Janice Y.S. Ho ${ }^{1, *}$ \\ 1 School of Nursing, Hong Kong Polytechnic University, Hong Kong, China; teris.cheung@polyu.edu.hk (T.C.); \\ chun-kwan.siu@connect.polyu.edu.hk (C.K.S.); ting-hei-rex.chan@connect.polyu.edu.hk (R.T.H.C.) \\ 2 The Jockey Club School of Public Health and Primary Care, Faculty of Medicine, the Chinese University of \\ Hong Kong, Hong Kong, China; jlau@cuhk.edu.hk (J.T.F.L.); wangzx@cuhk.edu.hk (J.Z.W.); \\ phoenix.mo@cuhk.edu.hk (P.M.) \\ 3 School of Public Health, Zhejiang University, Zhejiang 310058, Zhejiang Province, China \\ * Correspondence: janice.y.s.ho@polyu.edu.hk; Tel.: +852-27666410
}

Received: 30 March 2019; Accepted: 10 May 2019; Published: 14 May 2019

check for updates

\begin{abstract}
Background: Human papillomavirus (HPV) is one of the most common sexually transmitted infections nationwide. Methods: This is the first cross-sectional survey assessing physicians' and nurses' knowledge of HPV and recording their attitudes to HPV vaccination in Hong Kong. Survey questions were derived from the Health Belief Model. Results: 1152 clinicians (170 physicians and 982 nurses) aged 21 and 60 participated in this study. A multiple stepwise regression model was used to examine associations between cognitive factors (clinicians' attitudes) and subjects' intention to HPV vaccine uptake. Results showed that only $30.2 \%$ of physicians and $21.2 \%$ nurses found vaccinating for HPV acceptable. Conclusions: Perceived self-efficacy was the only significant background and cognitive variable associated with physicians' and nurses' accepting HPV vaccines. Further, when nurses found HPV vaccination acceptable, cues to action was featured as a significant background variable in their choice.
\end{abstract}

Keywords: HPV vaccine; acceptability; physicians; nurses; self-efficacy

\section{Introduction}

Human papillomavirus (HPV) is a well-known cause of cervical cancer and anogenital warts. HPV-16 and HPV-18 are the most common high-risk HPV forms associated with cervical cancer [1]; HPV-6 and HPV-11 are lower-risk viruses causing anogenital warts. Genital HPV infections are mainly transmitted by sexual contact (both vaginal and anal) with an infected person [2]. In order to prevent HPV infection, people can either abstain from sex or practice safer sex using condoms. They can further cut the risk of infection by having fewer sexual partners. However, epidemiologic studies suggest that up to $75 \%$ of all sexually active people will eventually become infected with HPV at some point during their lifetime [3].

In 2015, 500 new cases of cervical cancer were diagnosed at a crude incidence rate was 12.7 per 100,000 women in Hong Kong. Cervical cancer is the seventh commonest cancer among Hong Kong women. It accounts for $3.3 \%$ of all new cancer cases in females and is the ninth leading cause of all female cancer deaths. In 2016, a total of 151 women died of cervical cancer, representing $2.6 \%$ of female cancer deaths in Hong Kong [1]. Nevertheless, results from a recent Population Health Survey in 2014/15 found that the percentages of the relevant population between the ages of 25 and 64 (those 
ever screened and screened within the past three years) getting a cervical smear stood at $59 \%$ and $47 \%$, respectively $[4,5]$.

A recent systematic review (28 studies) [6] examined the acceptability of the HPV vaccination among adolescents (together with factors associated with its uptake and with adolescents declining the vaccine). Results showed the rate of vaccination across settings ranged from $2.4 \%$ to $94.4 \%$. Scotland had the highest HPV vaccination uptake, while Hong Kong had the lowest (2.4\% to $9.1 \%)$.

A recent local study asked 300 parents their views on the acceptability of HPV vaccination for their children (162 boys, 138 girls) aged 9 to 13. Results showed that the prevalence of HPV vaccination was very low ( $0.6 \%$ for boys against $2.2 \%$ for girls) [7].

Yuen et al. [8] conducted a local study examining the facilitators of, and barriers preventing, HPV vaccination. A total of 1229 girls aged 9 to 14 participated and were offered bivalent dose at 0 and 6 months for the period of a year. The vaccine uptake was $81.4 \%$ for the first HPV dose and $80.8 \%$ for the second. Yuen and colleagues found that two factors (the desire to prevent cervical cancer and doctors' recommendation) were significantly associated with parents' decision to vaccinate their daughters. Parents who had never heard of the HPV vaccine, had concerns about vaccination costs or preferred for their children to be vaccinated in a private clinic were less likely to allow their daughters to join the programme. The main reason parents refused to allow their daughters the shots was that they were worried about side effects. Another study conducted by Wang et al. [9] found that anxiety about their daughters getting cervical cancer was the most significant predictor of parental intention to get their daughters vaccinated among Chinese mothers in Hong Kong. Social influences and beliefs also affect parental intention regarding vaccination.

Past research on the acceptability of vaccination against HPV has focused on men having sex with men (SMS) [10], on female attitudes [11], parental attitudes [12-17], maternal attitudes [8,9,18,19]), and the views of baccalaureate students [20], secondary school pupils and adolescent girls [8,21-23]. Other research has focused on physicians' attitudes towards prescribing HPV vaccines to patients [24,25]. Very little research examines physicians' and nurses' attitudes towards the acceptability of HPV vaccination or the barriers physicians have encountered in recommending HPV vaccination in the last decade [26]. Physicians and nurses are role models, whose advice is central in the promotion of good health among their patients. An understanding of clinicians' knowledge of, and attitudes towards, HPV vaccination may begin to explain the low rate of HPV vaccine uptake in Hong Kong. The study aims to examine doctors' and nurses' views on the acceptability of vaccination against HPV and to determine associations between their perceptions of HPV and separately specifiable factors.

\section{The Health Belief Model and Outcome Measures}

Extensive research has been conducted using the Health Belief Model (HBM) to examine attitudes to and beliefs about HPV and HPV vaccination. This study incorporated the HBM to explain and predict health behaviour. The HBM is a theoretical framework commonly used to guide public health interventions [27]. Its presumption is that individuals who feel susceptible to consequences in terms of their health may change their behaviour when the benefits outweigh the barriers to change or costs of adopting a new behavior [28]. Their perceived vulnerability to ill health, the perceived severity of disease (or discomfort), perceived benefit of changing, perceived barriers to change, cues to action, and self-efficacy (perceived effectiveness of their actions) are the constructs of the HBM.

\section{Materials and Methods}

\subsection{Design, Setting and Participants}

The study implemented a cross-sectional self-administrative survey using purposive sampling. Participants were recruited from public hospitals in Hong Kong. To be included, subjects needed to be male or female, licensed physicians or qualified nurses, aged between 21 and 60, and currently working full-time under the Hospital Authority (the key healthcare provider in Hong Kong). They 
needed to be able to read the survey language, Chinese. Part-time employees and non-readers of Chinese were excluded from the study. Participants were recruited in the hospital communal areas by research assistants who introduced the study's aims and objectives. Respondents' confidentiality and anonymity were assured. Participants were given a self-addressed blank envelope containing an information sheet and our survey. They were asked to return completed surveys in a sealed envelope to the research assistants on-site. Returning a completed survey implied consent. A total of 1152 eligible participants were recruited to participate in this study from June to July 2017.

\subsection{Main Study Measures}

The survey filled in by participants had 21 items and closely followed the format of Lau's comparable study [10]. It solicited socio-demographic information including any personal history of sexually transmitted infection (STI) (both symptoms and diagnoses) and participants' number of sexual partners over the past six months. Participants expressed views on the acceptability of vaccination on a 5-point Likert scale ranging from 0-5 (0: they found vaccination highly acceptable, or it was "very likely" they would take up vaccination, to 5: it was "very unlikely" they would take up vaccination). Four questions were asked concerning whether participants had suffered HPV-related symptoms in the past year including (1) Did you experience any burning sensation in voiding or micturition? (yes/no); (2) Did you notice any presence of white / yellowish urethral secretion? (yes/no); (3) Have you experienced any prominent growth around the genital skin or mucosa? (yes/no), and (4) Have you had any prominent lumps around the genital skin or mucosa? (yes/no). The survey also asked respondents what they knew about, and how they thought about, HPV and HPV vaccines (or how they "cognized" these, in terms of the HBM). Six composite indicator variables were constructed by counting the number of affirmative item responses reflecting how far respondents believed they were susceptible to infection by HPV ( 0 to 3$)$, how severe they believed the infection was ( 0 to 3$)$, whether they perceived vaccination could benefit them ( 0 to 5$)$, how hard they thought it would be for get vaccinated ( 0 to 5$)$, whether they thought they could vaccinate themselves easily ( 0 to 2$)$ and whether they were cued to take the HPV vaccination by the media, doctors and peers (0 to 2$)$.

\subsection{Data Management and Statistical Analysis}

The statistical analysis was carried out separately among physicians and nurses because each had a different role in HPV vaccination (i.e., prescribing as against administration). Univariate logistic regression was conducted to select significant background variables, as well as significant composite cognitive indicator variables associated with the intention to take up HPV. Odds ratios were first presented in the course of univariate analysis $\left(\mathrm{OR}_{U}\right)$. A multiple stepwise regression model was then established using the significant univariate background variables as candidates; this allowed the calculation of multivariate odds ratios (ORm). Relationships between the cognitive indicator variables and dependent variable (respondents' intention of taking up HPV vaccination) were then assessed, adjusting for those background variables found to be significant in the multivariate analysis; adjusted odds ratios (AOR) were also determined. Odds ratios at 95\% confidence intervals (CI) were presented. Statistical analyses were performed using the statistical software SAS 9.2, with $p$ values of 0.05 taken as statistically significant.

\subsection{Ethics}

This study was approved by the Human Subjects Ethics Sub-committee, the Institutional Review Board of a local university in Hong Kong (reference no: HSEARS20170418004). 


\section{Results}

\subsection{Socio-Demographic Background Characteristics of the Participants}

A total of 1152 participants (170 physicians and 982 nurses) took part in this study. Most physician participants were male $(62.9 \%)$ and most nurse participants were female $(76.3 \%)$. About two-thirds $(63.5 \%)$ of physicians and $54.2 \%$ of nurses were single. Over $80 \%$ of physicians $(86.4 \%)$ and nurses $(83.7 \%)$ were below 40 years old, with the rest of participants ranged from 41 and 60 years old. Approximately half of the participants were not religious. All the physicians had at least a bachelor's degree, while only $56.7 \%$ of nurses had this level of qualification. Over half of the participants ( $57.1 \%$ physicians and $50.3 \%$ nurses) had less than five years clinical experience. Less than $30 \%$ of the physicians and nurses had more than 10 years of experience. Over $90 \%$ of physicians and nurses were frontline staff. $84.1 \%$ of physicians had a monthly income of HK\$60,000 ( USD 7645) or more; however, about three quarters of the nurses $(72.7 \%)$ had a monthly income of less than HK\$60,000.

The doctors had on average more than $50 \%$ more sexual partners than the nurses (1.2 average for the physicians against $0.6 \%$ for the nurses). However, more nurses $(19.9 \%)$ reported more than ten sexual partners than the doctors $(17.6 \%) .6 .6 \%$ of nurses and $4.2 \%$ of physicians exhibited had exhibited symptoms relating to STD in the past 6 months (Table 1).

Table 1. Frequency distributions of the background variables $(N=1152)$.

\begin{tabular}{|c|c|c|c|c|}
\hline \multirow{2}{*}{ Variable } & \multicolumn{2}{|c|}{ Physician $(N=170)$} & \multicolumn{2}{|c|}{ Nurse $(N=982)$} \\
\hline & $\mathbf{N}$ & $\%$ & $\mathbf{N}$ & $\%$ \\
\hline \multicolumn{5}{|l|}{ Gender } \\
\hline Male & 107 & 62.9 & 233 & 23.7 \\
\hline Female & 63 & 37.1 & 749 & 76.3 \\
\hline \multicolumn{5}{|l|}{ Age group } \\
\hline $21-29$ & 99 & 58.2 & 528 & 53.8 \\
\hline $30-39$ & 48 & 28.2 & 294 & 29.9 \\
\hline $40-60$ & 23 & 13.5 & 160 & 16.3 \\
\hline \multicolumn{5}{|l|}{ Education Level } \\
\hline Higher Diploma & 0 & 0.0 & 285 & 29.0 \\
\hline Degree & 144 & 84.7 & 557 & 56.7 \\
\hline Master or Above & 26 & 15.3 & 140 & 14.3 \\
\hline \multicolumn{5}{|l|}{ Marital Status } \\
\hline Unmarried & 108 & 63.5 & 532 & 54.2 \\
\hline Married & 62 & 36.5 & 450 & 45.8 \\
\hline \multicolumn{5}{|l|}{ Occupation } \\
\hline Doctor & 156 & 91.8 & 0 & 0.0 \\
\hline Psychiatrist & 2 & 1.2 & 0 & 0.0 \\
\hline Houseman & 12 & 7.1 & 0 & 0.0 \\
\hline RN (General) & 0 & 0.0 & 797 & 81.2 \\
\hline EN (General) & 0 & 0.0 & 90 & 9.2 \\
\hline RN (Psychiatric) & 0 & 0.0 & 68 & 6.9 \\
\hline EN (Psychiatric) & 0 & 0.0 & 14 & 1.4 \\
\hline Midwife & 0 & 0.0 & 13 & 1.3 \\
\hline \multicolumn{5}{|l|}{ Income (HK\$) } \\
\hline $20,001-40,000$ & 8 & 4.7 & 317 & 32.3 \\
\hline $40,001-60,000$ & 19 & 11.2 & 397 & 40.4 \\
\hline $60,001-80,000$ & 60 & 35.3 & 153 & 15.6 \\
\hline $80,001-100,000$ & 32 & 18.8 & 73 & 7.4 \\
\hline$>100,001$ & 51 & 30.0 & 42 & 4.3 \\
\hline
\end{tabular}


Table 1. Cont.

\begin{tabular}{|c|c|c|c|c|}
\hline \multirow{2}{*}{ Variable } & \multicolumn{2}{|c|}{ Physician $(N=170)$} & \multicolumn{2}{|c|}{ Nurse $(N=982)$} \\
\hline & $\mathbf{N}$ & $\%$ & $\mathbf{N}$ & $\%$ \\
\hline \multicolumn{5}{|l|}{ Religion } \\
\hline Yes & 78 & 45.9 & 477 & 48.6 \\
\hline No & 92 & 54.1 & 505 & 51.4 \\
\hline \multicolumn{5}{|l|}{ Years of experience } \\
\hline $0-5$ & 97 & 57.1 & 494 & 50.3 \\
\hline $6-10$ & 41 & 24.1 & 262 & 26.7 \\
\hline $11-20$ & 27 & 15.9 & 141 & 14.4 \\
\hline $21-40$ & 5 & 2.9 & 85 & 8.7 \\
\hline \multicolumn{5}{|l|}{ Main duties } \\
\hline Clinical & 167 & 98.2 & 901 & 91.8 \\
\hline Research & 4 & 2.4 & 1 & 0.1 \\
\hline Administration & 2 & 1.2 & 26 & 2.6 \\
\hline Community & 0 & 0.0 & 44 & 4.5 \\
\hline \multicolumn{5}{|c|}{ STD-related symptoms } \\
\hline Yes & 7 & 4.2 & 64 & 6.6 \\
\hline No & 159 & 95.8 & 910 & 93.4 \\
\hline \multicolumn{5}{|c|}{ Number of sex partners (past 6 months) } \\
\hline 0 & 65 & 40.4 & 327 & 33.7 \\
\hline 1 & 94 & 58.4 & 638 & 65.7 \\
\hline$\geq 2$ & 2 & 1.2 & 6 & 0.6 \\
\hline \multicolumn{5}{|c|}{ Sexual behaviors (past 6 months) } \\
\hline 0 & 66 & 43.1 & 362 & 37.7 \\
\hline $1-5$ & 37 & 24.2 & 236 & 24.6 \\
\hline $6-10$ & 23 & 15.0 & 172 & 17.9 \\
\hline$\geq 10$ & 27 & 17.6 & 191 & 19.9 \\
\hline
\end{tabular}

3.2. Intention to Take Up HPV Vaccines (Acceptability), Knowledge on HPV Vaccines and Perceived Self-Efficacy

A total of $30.2 \%$ of physicians and $21.2 \%$ nurses reported an intention to get vaccinated against HPV (Table 2). Less than $40 \%$ of physicians $(36 \%, n=64)$ obtained $\geq$ five correct responses on knowledge of HPV vaccine compared to $44.4 \%$ of nurses $(n=436) .70 \%$ of physicians and $63 \%$ of nurses disagreed that they were not motivated in the HPV vaccine uptake. Rather, $37-41 \%$ of nurses and physicians respectively believed that they should take the HPV vaccination. Both physicians and nurses had a relatively high percentage of perceived self-efficacy to complete the full treatment ( $82 \%$ versus $85 \%)$ and a significant proportion of physicians and nurses $(94 \%$ versus $97 \%$ ) alleged that they were fully autonomous to take up the HPV vaccination if indicated. Physicians and nurses received peer support $(76.5 \%$ versus $70.5 \%)$ and family support to take up the HPV vaccination $(78.2 \%$ versus $69.3 \%$ ).

Table 2. Perceptions related to HPV vaccines and intention to take up to HPV vaccines.

\begin{tabular}{lcccc}
\hline \multirow{2}{*}{ Variable } & \multicolumn{2}{c}{ Physician $(\boldsymbol{N}=\mathbf{1 7 0})$} & \multicolumn{2}{c}{ Nurse $(\mathbf{N}=\mathbf{9 8 2})$} \\
\cline { 2 - 5 } & $\mathbf{N}$ & $\mathbf{\%}$ & $\mathbf{N}$ & $\mathbf{\%}$ \\
\hline Knowledge on HPV vaccines & & & & \\
\hline Availability of effective HPV vaccines & & & & \\
\hline No/Don't know & 11 & 6.5 & 201 & 20.5 \\
Yes & 159 & 93.5 & 781 & 79.5 \\
\hline
\end{tabular}


Table 2. Cont.

\begin{tabular}{|c|c|c|c|c|}
\hline \multirow{2}{*}{ Variable } & \multicolumn{2}{|c|}{ Physician $(N=170)$} & \multicolumn{2}{|c|}{ Nurse $(N=982)$} \\
\hline & $\mathbf{N}$ & $\%$ & $\mathbf{N}$ & $\%$ \\
\hline \multicolumn{5}{|l|}{ Knowledge on HPV vaccines } \\
\hline \multicolumn{5}{|l|}{ Availability of HPV 2/4/9 valent } \\
\hline Yes* & 143 & 84.1 & 691 & 70.4 \\
\hline No/Don't know & 27 & 15.9 & 291 & 29.6 \\
\hline \multicolumn{5}{|c|}{ Perceived price per shot $(\mathrm{HK} \$: 1 \mathrm{US} \$=7.8 \mathrm{HK} \$)$} \\
\hline$<800 />1500 /$ Don't know & 86 & 50.6 & 502 & 51.1 \\
\hline $800-1500 *$ & 84 & 49.4 & 480 & 48.9 \\
\hline \multicolumn{5}{|l|}{ Number of shots required } \\
\hline 1-2/Don't know & 62 & 36.5 & 372 & 37.9 \\
\hline $3 *$ & 108 & 63.5 & 610 & 62.1 \\
\hline \multicolumn{5}{|l|}{ Duration of protection } \\
\hline$<2$ year/2-5 years/Lifelong/Don't know & 134 & 78.8 & 750 & 76.4 \\
\hline $6-10$ years * & 36 & 21.2 & 232 & 23.6 \\
\hline \multicolumn{5}{|l|}{ Age group suggested for HPV vaccination } \\
\hline Above 30 years old/Don't know & 25 & 14.7 & 257 & 26.2 \\
\hline Below 30 years old * & 145 & 85.3 & 725 & 73.8 \\
\hline \multicolumn{5}{|l|}{$\begin{array}{l}\text { Number of appropriate responses to the above } \\
\text { questions on knowledge of HPV vaccines }\end{array}$} \\
\hline 0 & 8 & 4.7 & 188 & 19.1 \\
\hline 1 & 2 & 1.2 & 9 & 0.9 \\
\hline 2 & 13 & 7.6 & 34 & 3.5 \\
\hline 3 & 22 & 12.9 & 107 & 10.9 \\
\hline 4 & 61 & 35.9 & 208 & 21.2 \\
\hline$\geq 5$ & 64 & 37.6 & 436 & 44.4 \\
\hline
\end{tabular}

Perceived benefits of HPV Vaccines for preventing and treating diseases related to HPV

\begin{tabular}{|c|c|c|c|c|}
\hline \multicolumn{5}{|c|}{ Perceived efficacy in preventing genital warts } \\
\hline No/Neutral & 49 & 28.8 & 470 & 47.9 \\
\hline Yes & 121 & 71.2 & 512 & 52.1 \\
\hline \multicolumn{5}{|c|}{ Perceived efficacy in preventing HPV-induced cancers } \\
\hline No/Neutral & 17 & 10.0 & 290 & 29.5 \\
\hline Yes & 153 & 90.0 & 692 & 70.5 \\
\hline \multicolumn{5}{|c|}{ Perceived efficacy in preventing STD other than genital warts } \\
\hline No/Neutral & 126 & 74.1 & 657 & 66.9 \\
\hline Yes & 44 & 25.9 & 325 & 33.1 \\
\hline \multicolumn{5}{|c|}{ Perceived efficacy in treating genital warts } \\
\hline No/Neutral & 150 & 88.2 & 846 & 86.2 \\
\hline Yes & 20 & 11.8 & 136 & 13.8 \\
\hline \multicolumn{5}{|c|}{$\begin{array}{l}\text { Healthcare professionals are less motivation to take } \\
\text { HPV vaccination }\end{array}$} \\
\hline Totally disagree/disagree & 119 & 70.0 & 619 & 63.0 \\
\hline Totally agree/agree & 43 & 25.3 & 356 & 36.3 \\
\hline Don't know & 8 & 4.7 & 7 & 0.7 \\
\hline \multicolumn{5}{|c|}{ Healthcare professionals should take HPV vaccination } \\
\hline Totally disagree/disagree & 93 & 54.7 & 609 & 62.0 \\
\hline Totally agree/agree & 69 & 40.6 & 364 & 37.1 \\
\hline Don't know & 8 & 4.7 & 9 & 0.9 \\
\hline \multicolumn{5}{|c|}{$\begin{array}{l}\text { Number of item responses to the above nine questions } \\
\text { reflecting perceived barriers related to HPV } \varphi\end{array}$} \\
\hline 0 & 14 & 8.2 & 81 & 8.2 \\
\hline 1 & 45 & 26.5 & 89 & 9.1 \\
\hline 2 & 35 & 20.6 & 223 & 22.7 \\
\hline
\end{tabular}


Table 2. Cont.

\begin{tabular}{|c|c|c|c|c|}
\hline \multirow{2}{*}{ Variable } & \multicolumn{2}{|c|}{ Physician $(N=170)$} & \multicolumn{2}{|c|}{ Nurse $(N=982)$} \\
\hline & $\mathbf{N}$ & $\%$ & $\mathbf{N}$ & $\%$ \\
\hline 3 & 35 & 20.6 & 222 & 22.6 \\
\hline 4 & 23 & 13.5 & 162 & 16.5 \\
\hline$\geq 5$ & 18 & 10.6 & 205 & 20.9 \\
\hline \multicolumn{5}{|l|}{ Perceived self-efficacy to take up HPV vaccines } \\
\hline I can complete the full treatment & & & 146 & 14.9 \\
\hline Disagree & 30 & 17.6 & 836 & 85.1 \\
\hline Agree & 140 & 82.4 & & \\
\hline I have autonomy on whether taking up HPV vaccines & & & 32 & 3.3 \\
\hline Disagree & 10 & 5.9 & 950 & 96.7 \\
\hline Agree & 160 & 94.1 & & \\
\hline $\begin{array}{l}\text { Number of item responses to the above } 2 \text { questions } \\
\text { reflecting perceived self-efficacy } \varphi\end{array}$ & & & 29 & 3.0 \\
\hline 0 & 7 & 4.1 & 120 & 12.2 \\
\hline 1 & 26 & 15.3 & 833 & 84.8 \\
\hline 2 & 137 & 80.6 & & \\
\hline \multicolumn{5}{|l|}{ Perceived support to take up HPV vaccines } \\
\hline Family members support me to take up HPV vaccines & & & 681 & 69.3 \\
\hline Yes & 133 & 78.2 & 41 & 4.2 \\
\hline No & 4 & 2.4 & 260 & 26.5 \\
\hline Don't know & 33 & 19.4 & & \\
\hline Peers support me to take up HPV vaccines & & & 692 & 70.5 \\
\hline Yes & 130 & 76.5 & 33 & 3.4 \\
\hline No & 7 & 4.1 & 257 & 26.2 \\
\hline Don't know & 33 & 19.4 & & \\
\hline $\begin{array}{l}\text { Number of item responses to the above } 2 \text { questions } \\
\text { reflecting perceived supports } \varphi\end{array}$ & & & 247 & 25.2 \\
\hline 0 & 33 & 19.4 & 97 & 9.9 \\
\hline 1 & 11 & 6.5 & 638 & 65.0 \\
\hline 2 & 126 & 74.1 & & \\
\hline \multicolumn{5}{|l|}{ Cue to action } \\
\hline \multicolumn{5}{|l|}{ Doctor recommended me to take up HPV vaccines } \\
\hline Yes & 89 & 52.4 & 384 & 39.1 \\
\hline No & 22 & 12.9 & 182 & 18.5 \\
\hline Don't know & 59 & 34.7 & 416 & 42.4 \\
\hline \multicolumn{5}{|l|}{ Peers recommended me to take up HPV vaccines } \\
\hline Yes & 80 & 47.1 & 455 & 46.3 \\
\hline No & 33 & 19.4 & 246 & 25.1 \\
\hline Don't know & 57 & 33.5 & 281 & 28.6 \\
\hline \multicolumn{5}{|l|}{$\begin{array}{l}\text { I have watched media reports promoting HPV } \\
\text { vaccines }\end{array}$} \\
\hline Yes & 130 & 76.5 & 770 & 78.4 \\
\hline No & 13 & 7.6 & 114 & 11.6 \\
\hline Don't know & 27 & 15.9 & 98 & 10.0 \\
\hline \multicolumn{5}{|l|}{$\begin{array}{l}\text { I will recommend my patients/their family members } \\
\text { to take up HPV vaccines }\end{array}$} \\
\hline Yes & 141 & 82.9 & 580 & 59.1 \\
\hline No & 29 & 17.1 & 402 & 40.9 \\
\hline \multicolumn{5}{|l|}{$\begin{array}{l}\text { Number of item responses to the above four questions } \\
\text { reflecting cue to action received } \varphi\end{array}$} \\
\hline 0 & 17 & 10.0 & 119 & 12.1 \\
\hline 1 & 19 & 11.2 & 177 & 18.0 \\
\hline 2 & 42 & 24.7 & 244 & 24.8 \\
\hline
\end{tabular}


Table 2. Cont

\begin{tabular}{|c|c|c|c|c|}
\hline \multirow{2}{*}{ Variable } & \multicolumn{2}{|c|}{ Physician $(N=170)$} & \multicolumn{2}{|c|}{ Nurse $(N=982)$} \\
\hline & $\mathbf{N}$ & $\%$ & $\mathbf{N}$ & $\%$ \\
\hline 3 & 31 & 18.2 & 244 & 24.8 \\
\hline 4 & 61 & 35.9 & 198 & 20.2 \\
\hline \multicolumn{5}{|c|}{ Behavioral intention to take up HPV vaccines } \\
\hline \multicolumn{5}{|c|}{ Intention to take up HPV vaccines } \\
\hline Very likely & 8 & 6.9 & 33 & 4.6 \\
\hline Quite likely & 27 & 23.3 & 119 & 16.6 \\
\hline Not quite likely & 59 & 50.9 & 431 & 60.1 \\
\hline Not likely & 22 & 19.0 & 134 & 18.7 \\
\hline
\end{tabular}

* Appropriate response. ${ }^{\varphi}$ Number of affirmative responses (totally agree/agree, yes).

\subsection{Knowledge on HPV}

The proportion giving a correct answer on individual knowledge items on HPV ranged from $50.6 \%$ to $95.3 \%$ among physicians and $51.6 \%$ to $93.6 \%$ in nurses (Table 3). Both groups had misconceptions about HPV, for instance, that the virus could not be transmitted through sex, and infection was totally curable, and that HPV 16 was able to cause genital warts. Nurses also believed that HPV could be controlled by antibiotics, that HPV was hereditary, and that HPV 18 could cause genital warts (Table 3).

Table 3. Frequency distributions of variables related to HPV-related perceptions $(\mathrm{N}=1152)$.

\begin{tabular}{|c|c|c|c|c|}
\hline \multirow{2}{*}{ Variable } & \multicolumn{2}{|c|}{ Physician $(N=170)$} & \multicolumn{2}{|c|}{ Nurse $(N=982)$} \\
\hline & $\mathbf{N}$ & $\%$ & $\mathbf{N}$ & $\%$ \\
\hline \multicolumn{5}{|l|}{ Knowledge on HPV } \\
\hline \multicolumn{5}{|l|}{ Whether males or female could be affected by HPV } \\
\hline Only Male & 2 & 1.2 & 4 & 0.4 \\
\hline Only Female & 4 & 2.4 & 44 & 4.5 \\
\hline Both * & 162 & 95.3 & 919 & 93.6 \\
\hline Don't know & 2 & 1.2 & 15 & 1.5 \\
\hline \multicolumn{5}{|l|}{ Route of HPV transmission } \\
\hline Both sexual and Mother-to-infant transmission * & 86 & 50.6 & 507 & 51.6 \\
\hline Other route/Don't know & 84 & 49.4 & 475 & 48.4 \\
\hline \multicolumn{5}{|l|}{ HPV6 \& HPV11 cause Genital Warts } \\
\hline Yes* & 142 & 83.5 & 586 & 59.7 \\
\hline No/Don't know & 28 & 16.5 & 396 & 40.3 \\
\hline \multicolumn{5}{|l|}{ HPV16 causes Genital Warts } \\
\hline Yes/Don't know & 45 & 26.5 & 436 & 44.4 \\
\hline $\mathrm{No}^{*}$ & 122 & 71.8 & 535 & 54.5 \\
\hline \multicolumn{5}{|l|}{ HPV18 causes Genital Warts } \\
\hline Yes/Don't know & 11 & 6.5 & 193 & 19.7 \\
\hline $\mathrm{No}^{*}$ & 159 & 93.5 & 789 & 80.3 \\
\hline \multicolumn{5}{|l|}{ HPV could be controlled by antibiotics } \\
\hline Yes/Don't know & 11 & 6.5 & 193 & 19.7 \\
\hline $\mathrm{No}^{*}$ & 159 & 93.5 & 789 & 80.3 \\
\hline \multicolumn{5}{|l|}{ HPV could be completely cured } \\
\hline Yes/Don't know & 66 & 38.8 & 419 & 42.7 \\
\hline $\mathrm{No}^{*}$ & 104 & 61.2 & 563 & 57.3 \\
\hline \multicolumn{5}{|l|}{ HPV is hereditary } \\
\hline Yes/Don't know & 19 & 11.2 & 169 & 17.2 \\
\hline $\mathrm{No}^{*}$ & 151 & 88.8 & 813 & 82.8 \\
\hline
\end{tabular}


Table 3. Cont.

\begin{tabular}{|c|c|c|c|c|}
\hline \multirow{2}{*}{ Variable } & \multicolumn{2}{|c|}{ Physician $(N=170)$} & \multicolumn{2}{|c|}{ Nurse $(N=982)$} \\
\hline & $\mathbf{N}$ & $\%$ & $\mathbf{N}$ & $\%$ \\
\hline \multicolumn{5}{|c|}{$\begin{array}{l}\text { Number of appropriate responses to the above questions } \\
\text { on knowledge related to HPV } \varphi\end{array}$} \\
\hline 0 & 0 & 0.0 & 3 & 0.3 \\
\hline 1 & 0 & 0.0 & 7 & 0.7 \\
\hline 2 & 4 & 2.4 & 34 & 3.5 \\
\hline 3 & 13 & 7.6 & 62 & 6.3 \\
\hline 4 & 28 & 16.5 & 186 & 18.9 \\
\hline 5 & 52 & 30.6 & 272 & 27.7 \\
\hline$\geq 6$ & 73 & 42.9 & 418 & 42.6 \\
\hline \multicolumn{5}{|c|}{ Perceived severity of HPV infection } \\
\hline \multicolumn{5}{|c|}{ Perceived chance of contracting HPV in the future } \\
\hline Low/very low & 79 & 46.5 & 508 & 51.7 \\
\hline Moderate & 75 & 44.1 & 418 & 42.6 \\
\hline Very high/high & 16 & 9.4 & 56 & 5.7 \\
\hline \multicolumn{5}{|c|}{ Perceived damages of HPV infection on physical health } \\
\hline Low/very low & 9 & 5.3 & 36 & 3.7 \\
\hline Moderate & 76 & 44.7 & 359 & 36.6 \\
\hline Very high/high & 85 & 50.0 & 587 & 59.8 \\
\hline \multicolumn{5}{|c|}{ Perceived infectivity of HPV } \\
\hline Low/very low & 0 & 0.0 & 112 & 11.4 \\
\hline Moderate & 77 & 45.3 & 453 & 46.1 \\
\hline Very high/high & 93 & 54.7 & 417 & 42.5 \\
\hline \multicolumn{5}{|c|}{$\begin{array}{l}\text { Number of appropriate responses to the above questions } \\
\text { reflecting perceived severity } \varphi\end{array}$} \\
\hline 0 & 50 & 29.4 & 332 & 33.8 \\
\hline 1 & 55 & 32.4 & 266 & 27.1 \\
\hline$\geq 2$ & 65 & 38.2 & 384 & 39.1 \\
\hline \multicolumn{5}{|c|}{ Perceived susceptibility of HPV infection } \\
\hline \multicolumn{5}{|c|}{ Perceived knowledge on HPV } \\
\hline Low/very low & 33 & 19.4 & 341 & 34.7 \\
\hline Moderate & 110 & 64.7 & 577 & 58.8 \\
\hline Very high/high & 27 & 15.9 & 64 & 6.5 \\
\hline \multicolumn{5}{|c|}{ Perceived prevalence of HPV infection among male } \\
\hline Low/very low & 18 & 10.6 & 175 & 17.8 \\
\hline Moderate & 89 & 52.4 & 564 & 57.4 \\
\hline Very high/high & 63 & 37.1 & 243 & 24.7 \\
\hline \multicolumn{5}{|c|}{ Perceived prevalence of HPV infection among female } \\
\hline Low/very low & 8 & 4.7 & 37 & 3.8 \\
\hline Moderate & 73 & 42.9 & 464 & 47.3 \\
\hline Very high/high & 89 & 52.4 & 481 & 49.0 \\
\hline \multicolumn{5}{|c|}{$\begin{array}{l}\text { Number of appropriate responses to the above questions } \\
\text { reflecting perceived susceptibility } \varphi\end{array}$} \\
\hline 0 & 72 & 42.4 & 460 & 46.8 \\
\hline 1 & 33 & 19.4 & 285 & 29.0 \\
\hline$\geq 2$ & 65 & 38.2 & 237 & 24.1 \\
\hline
\end{tabular}

${ }^{*}$ Appropriate response. ${ }^{\varphi}$ Number of affirmative responses (very high/high).

Regarding perceived susceptibility, $52.4 \%$ of physicians and $49.0 \%$ of nurses saw the risk of HPV infection among women as high or very high. By contrast, $37.1 \%$ of physicians and $24.7 \%$ of nurses thought that men could easily catch the disease. $54.7 \%$ of physicians and $42.5 \%$ nurses believed that HPV was highly infectious. Yet only $9.4 \%$ of physicians and $5.7 \%$ of nurses thought they had a high or very high chance of catching HPV. $19.4 \%$ of physicians and over one-third of nurses $(34.7 \%)$ were 
aware their knowledge of HPV was lacking. Exactly half and over half of the physicians and nurses (50.0\% vs. 59.8\%) understood that the HPV virus could harm persons' physical health (Table 3 ).

\subsection{Cognitions on HPV Vaccine}

The proportions of physicians and nurses who provided correct answers on items regarding knowledge of HPV vaccines (availability, price, the 3-shot requirement, expected duration of protection, the preferred age range for vaccination) varied, ranging from $21.2 \%$ to $93.5 \%$ in physicians and $23.6 \%$ to $79.5 \%$ in nurses. The prevalence of correct responses regarding the perceived benefits of vaccination for the physicians and nurses were similar: $71.2 \%$ (physicians) and $52.1 \%$ (nurses) knew it could prevent genital warts; $90.0 \%$ and $70.5 \%$ knew it could prevent, HPV-induced cancers $(90.0 \%$ vs. $70.5 \%) ; 25.9 \%$ vs. $33.1 \%$ knew it could prevents STDs other than HPV; and $11.8 \%$ vs. $13.8 \%$ knew it could treat genital warts. $11.8 \%$ of physicians and $14.8 \%$ of nurses knew the shots could treat HPV-induced cancers $(11.8 \%$ vs. $14.8 \%$ ) (Table 3$)$.

Physicians disagreed more often than nurses with statements suggesting there were serious barriers to vaccination. "HPV vaccines are expensive", had a $67.6 \%$ agreement rate in physicians and a $70.5 \%$ in nurses. "There are side effects" came in at $20.0 \%$ for physicians and $32.8 \%$ for nurses; "it is embarrassing to take up HPV vaccines", at $11.8 \%$ vs. $18.1 \%$, respectively; "private hospitals do not provide HPV vaccines", $10.0 \%$ vs. $23.8 \%$; "public hospitals do not provide HPV vaccination", $52.4 \%$ against $60.5 \%$; and "getting vaccinated against HPV means you are promiscuous", $5.3 \%$ against $7.9 \% .17 .6 \%$ of doctors and $23.0 \%$ of nurses thought it was easier for healthcare professionals to be infected with HPV. $25.3 \%$ of doctors and $36.3 \%$ of nurses agreed that "healthcare professionals are less motivated to take up HPV vaccination", while also thinking ( $40.6 \%$ doctors, $37.1 \%$ nurses) that "healthcare professionals should take up HPV vaccination". The level of perceived self-efficacy in taking up HPV vaccination was high in physicians ( $82.4 \%$ and $94.1 \%$ ) and nurses $(85.1 \%$ and $96.7 \%)$. Both groups thought their peers $(78.2 \%$ and $76.5 \%)$ and family members $(69.3 \%$ and $70.5 \%)$. The rate of responses regarding cues to action among physicians and nurses were that media reports $(76.5 \%$ vs. $78.4 \%$ ) were likely to encourage them to take up vaccination, as were doctors (52.4\% vs. $39.1 \%$ ) and to some extent, peers ( $47.1 \%$ vs. $46.3 \%$ ). $82.9 \%$ of physicians would recommend their patients or patients' family members to take up HPV vaccines, compared to only $59.1 \%$ of nurses (Table 3 ).

\subsection{Factors Associated with Acceptability of HPV Vaccines}

We found that gender was the only statistically significant background variable among physician participants. After adjusting for gender, the results showed four cognitive composite indicator variables as statistically significant. They were the perceived severity of disease (AOR $=2.689,95 \%$ $\mathrm{CI}=1.034-6.990)$, perceived self-efficacy in preempting it $(\mathrm{AOR}=5.408,95 \% \mathrm{CI}=1.466-19.945)$, perceived support (from family or peers) $(\mathrm{AOR}=3.468,95 \% \mathrm{CI}=1.191-10.099$ ) and cues to action $(\mathrm{AOR}=3.688,95 \% \mathrm{CI}=1.165-11.675)($ Table 4$)$.

Table 4. Associations between composite cognitive indicator variables and intention to take up HPV vaccines.

\begin{tabular}{cccc}
\hline Physician $^{\text {a }}$ & Row $\%$ & ORU (95\%CI) & AOR (95\%CI) \\
\hline & Perceived severity of HPV & (number of items with affirmative responses) \\
\hline 0 & 17.1 & 1 & 1 \\
$\geq 1$ & 37.3 & $2.894(1.132,7.396)$ & $2.689(1.034,6.990) *$ \\
\hline \multicolumn{4}{r}{ Perceived self-efficacy to take up HPV (number of items with affirmative responses) } \\
\hline 0 or 1 & 10.3 & 1 & 1 \\
2 & 36.8 & $5.042(1.413,17.992) *$ & $5.408(1.466,19.945) *$ \\
\hline
\end{tabular}


Table 4. Cont.

\begin{tabular}{|c|c|c|c|}
\hline Physician ${ }^{\text {a }}$ & Row \% & ORU $(95 \% \mathrm{CI})$ & AOR $(95 \% C I)$ \\
\hline \multicolumn{4}{|c|}{ Perceived support to take up HPV (number of items with affirmative responses) } \\
\hline 0 or 1 & 14.3 & 1 & 1 \\
\hline 2 & 37.0 & $3.529(1.237,10.072) *$ & $3.468(1.191,10.099) *$ \\
\hline \multicolumn{4}{|c|}{ Cue to action to take up HPV (number of items with affirmative responses) } \\
\hline 0 or 1 & 12.5 & 1 & 1 \\
\hline$\geq 2$ & 36.9 & $4.093(1.313,12.767) *$ & $3.688(1.165,11.675) *$ \\
\hline \multicolumn{4}{|l|}{ Nurse ${ }^{b}$} \\
\hline \multicolumn{4}{|c|}{ Perceived susceptibility of HPV (number of items with affirmative responses) } \\
\hline 0 & 18.4 & 1 & 1 \\
\hline 1 & 21.8 & $1.242(0.808,1.908)$ & $1.204(0.765,1.896)$ \\
\hline$\geq 2$ & 27.1 & $1.653(1.062,2.573) *$ & $1.779(1.109,2.853) *$ \\
\hline \multicolumn{4}{|c|}{ Knowledge on HPV vaccines (number of items with correct answer) } \\
\hline 0 & 12.5 & 1 & 1 \\
\hline 1 or 2 & 7.5 & $0.568(0.160,2.014)$ & $0.656(0.179,2.404)$ \\
\hline 3 & 19.5 & $1.700(0.838,3.449)$ & $2.013(0.958,4.274)$ \\
\hline$\geq 4$ & 26.5 & $2.465(1.472,4.129)^{* * *}$ & $2.588(1.515,4.421)^{* *}$ \\
\hline \multicolumn{4}{|c|}{ Perceived benefits to take up HPV (number of items with affirmative responses) } \\
\hline 0 & 16.8 & 1 & 1 \\
\hline 1 & 14.2 & $0.822(0.463,1.461)$ & $0.860(0.462,1.600)$ \\
\hline 2 & 20.0 & $1.241(0.691,2.229)$ & $1.011(0.544,1.880)$ \\
\hline$\geq 3$ & 31.1 & $2.241(1.367,3.676) * *$ & $1.815(1.076,3.063) *$ \\
\hline \multicolumn{4}{|c|}{ Perceived self-efficacy to take up HPV (number of items with affirmative responses) } \\
\hline 0 or 1 & 9.7 & 1 & 1 \\
\hline 2 & 23.6 & $2.884(1.544,5.387)^{* * *}$ & $2.772(1.422,5.401) * *$ \\
\hline \multicolumn{4}{|c|}{ Perceived support to take up HPV (number of items with affirmative responses) } \\
\hline 0 & 12.7 & 1 & 1 \\
\hline 1 & 24.1 & $2.181(1.133,4.200) *$ & $1.915(0.965,3.798)$ \\
\hline 2 & 24.9 & $2.289(1.446,3.625)^{* * *}$ & $2.206(1.360,3.576) * *$ \\
\hline \multicolumn{4}{|c|}{ Cue to action to take up HPV (number of items with affirmative responses) } \\
\hline 0 & 5.5 & 1 & 1 \\
\hline 1 & 13.0 & $2.575(1.004,6.607) *$ & $2.703(1.032,7.082)$ * \\
\hline$\geq 2$ & 28.0 & $6.664(2.852,15.570)^{* * *}$ & $6.960(2.918,16.597)^{* * *}$ \\
\hline
\end{tabular}

${ }^{*} p<0.05 ;{ }^{* *} p<0.01 ;{ }^{* * *} p<0.001 .^{\text {a }}$ AOR: adjusted OR, odds ratios after adjusting gender, which was the significant background variable. ${ }^{b}$ AOR: adjusted OR, odds ratios adjusted for all multivariate significant background variables, including gender, age group, STD-related symptoms and number of sexual behaviors in the past 6 months. $\mathrm{OR}_{\mathrm{U}}$ : univariate odds ratios. Univariate non-significant variables, not considered in the model. $95 \%$ CI: 95\% confidence interval.

Adjusting for these four variables, results showed that six of the composite cognitive indicator variables were statistically significant. These were knowledge of HPV vaccines (AOR $=2.588$, $p<0.01$ ), perceived susceptibility to HPV (AOR $=1.779, p<0.05$ ), the perceived benefits of vaccination $(\mathrm{AOR}=1.815, p<0.05)$, perceived self-efficacy $(\mathrm{AOR}=2.772, p<0.01)$, perceived support $(\mathrm{AOR}=2.206$, $p<0.01$ ) and cues to action (AOR $=2.703$ to $6.960, p<0.05$ ) (Table 4 ). In addition, the study fitted a multiple logistic regression model containing all the significant composite cognitive indicator variables and adjusted for significant background variables.

Four background variables were statistically significant among the nurse participants: (1) Gender $(\mathrm{ORm}=1.764,95 \% \mathrm{CI}=1.129-2.759)$, (2) age group (“21-29”: $\mathrm{ORm}=4.095,95 \% \mathrm{CI}=2.187-7.669$; "30-39": ORm $=1.627,95 \% \mathrm{CI}=0.802-3.301$, reference group was " $40 \&$ over"), (3) having STD-related symptoms $(\mathrm{ORm}=2.230,95 \% \mathrm{CI}=1.779-7.446)$, and (4) number of sexual acts in the past 6 months 
(“0”: ORm $=1.854,95 \%$ CI $=1.153-2.981 ; " 1-5$ ": ORm $=2.166,95 \% \mathrm{CI}=1.305-3.597$, the reference group was " 6 or more"). After fitting a multiple logistic regression model containing all the significant cognitive composite indicator variables, and adjusting for the same significant background variable, only perceived self-efficacy and cutes to action emerged as the only significant composite cognitive variables (Table 5).

Table 5. Multiple logistic regression result-associations between composite cognitive indicator variables and intention to take up HPV vaccines.

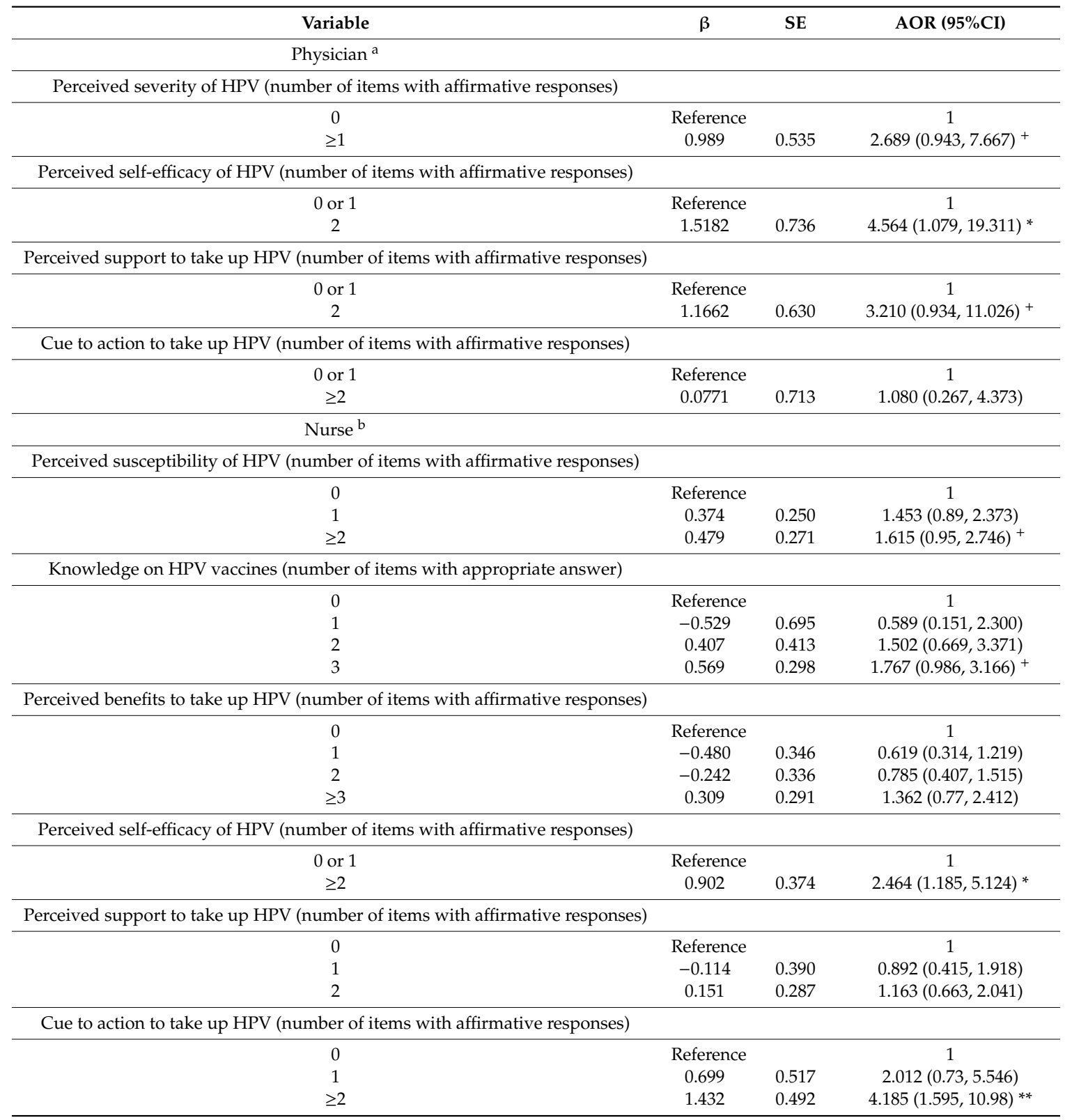

${ }^{*} p<0.05 ;{ }^{* *} p<0.01 .{ }^{* * *} p<0.001 .{ }^{+} 0.05<p<0.1 ;^{\text {a }}$ AOR: adjusted OR, odds ratios after adjusting gender and simultaneously for all involved variables. STD-related symptoms and number ${ }^{\mathrm{b}}$ AOR: adjusted OR, odds ratios after adjusting simultaneously for all involved variables and the significant background variables which include gender, age group, number of sexual behaviors in the past 6 months. 95\%CI: 95\% confidence interval. SE: Standard error.

\section{Discussion}

Results of multiple logistic regression suggest that self-efficacy is the only significant composite cognitive variable associated with physicians' and nurses' intention get vaccinated themselves against HPV. Nurses, further, are more likely to get vaccinated when they perceive that there are positive cues 
to action. We found that female physicians are three times more likely than male physicians to take up HPV vaccination. This finding is unsurprising: $37.1 \%$ of respondents giving this answer were female physicians, and $86.4 \%$ (of both genders) were below 40 years old; of this group, $59.6 \%$ had been sexually active in the past 6 months. Female physicians broadly exhibited a fundamental knowledge of HPV and other sexually-transmitted diseases and cervical cancers. The main driver of their behaviour in getting vaccinated, then, is likely to be to avoid infection [29].

The acceptability of the HPV vaccine among physicians and nurses in this study is relatively low $(30.2 \%$ as against $21.2 \%)$. We speculate that this low rate of acceptability may be attributed to 1 ) respondents having little or no exposure to STD-related symptoms themselves; 2 ) their having limited exposure to HPV in their clients in clinical settings; 3 ) their not knowing the risks of acquiring HPV transmission; 4) a misconception that HPV can be completely cured. One of the predictors for the acceptability of HPV vaccine take up is knowledge of HPV [30]. Some researchers have found that poor HPV knowledge is positively correlated with a low incidence of the intention to get vaccinated [31]. Our findings echoed Poole's claim. It is noteworthy that only $43 \%$ of physicians and nurses answered six or more questions on HPV correctly. This ignorance among physicians and nurses in this study was unexpectedly high. Clinical specialty may also contribute to participants' intention to take up an HPV vaccine. The possibility exists that our respondents rarely deal with young adolescents or are not confronted with patients with HPV in their clinical settings [25].

Lee and Wang [26] found that only $41.8 \%$ of healthcare providers (28 doctors and 70 nurses) would recommend HPV vaccination to their patients in sexually transmitted disease (STD) clinics in Hong Kong. It is interesting that physicians in the public hospitals were more willing to prescribe HPV vaccination than those working in STD clinics. It is encouraging to note that $82.9 \%$ of physician participants would recommend the HPV vaccination to their patients, despite rarely stating an intention to get the shots themselves. The large variation between physicians' recommendations and individual attitudes towards the acceptability of HPV vaccination may suggest that, knowing their own behaviour, clinicians suppose themselves less at risk. It may also suggest they take pride in their efficacy as clinicians to administer all three doses.

Hong Kong is a developed part of Asia with generally high incomes. Nevertheless, there is some evidence to suggest that the general public, in both high- and low-income countries, may know little about HPV, the risk factors for cervical cancer and genital warts [32]. Decisions whether to be vaccinated for HPV are affected by individual knowledge, beliefs about vulnerability, perception of the vaccine's effectiveness, family physicians' views, sexual practices, cultural norms, and the cost of vaccination [33,34]. Young adolescents may rely on their peers, parents, the mass media, private general practitioners or primary healthcare providers for cues to take proactive steps to take the vaccine [20]. Of all groups, parents are most important in encouraging children to take the shots. Wang et al. [12] used telephone interviews to assess the attitudes of 1996 Chinese parents of 12 to 17-year-old unvaccinated girls towards HPV vaccination. At a 1-year follow-up, less than $10 \%$ ( $n=97$ out of 979 parents) of these participants' daughters had received at least one dose of HPV vaccines. Wang's findings suggest that parents' ignorance risks their daughters' future health.

A healthcare provider's recommendation is one of the strongest, most consistent predictors of HPV vaccination, as evidenced by Chow et al. [33]'s survey of 480 physicians and 1,617 randomly selected mothers in Korea, Malaysia, Taiwan and Thailand. $94 \%$ of women surveyed were ignorant about $\mathrm{HPV} ; 58 \%$ of women asserted that doctors should initiate the conversation about HPV vaccination. In contrast, $61 \%$ of general practitioners, $28 \%$ obstetrician-gynecologists, and $56 \%$ pediatricians claimed to be incompetent to initiate a conversation about HPV vaccination with their clients in the absence of further training. This knowledge deficit may inevitably mean that physicians fail to prescribe HPV vaccine to their clients. This only suggests the need for physicians to keep up-to-date with the science relating to STDs to reduce the risk of HPV-related diseases [35].

The study sought to determine which factors were related to a physician's likelihood of initiating a conversation about HPV vaccination. They were likely to do so if they believed that, as professionals, 
they had a proactive role to play in educating women about cervical cancer and preventive health measures; if they had basic knowledge of HPV infections and vaccines; and felt comfortable raising the subject. Those less knowledgeable and with negative attitudes towards cervical cancer were less liable to begin a conversation about HPV vaccination. Some physicians may see discussions of HPV vaccination as burdensome, comparing to bringing up other vaccines offered adolescents [36]. Personal subjective bias and preferences in prescribing behaviour may lead to unnecessary delays in immunising adolescents.

It is interesting that nurses in our study suggested that 'cues to action' may increase their likelihood of taking up HPV vaccination. We speculate that these nurses are unlikely to come across clients suffering from STD-related diseases in their work. Their limited clinical exposure may reduce their effectiveness in caring for their own health. Tay et al. [36] surveyed 1622 nurses' intention of getting vaccinated and examined why women might decline HPV vaccination. Results showed very few nurses $(8.8 \%)$ had been vaccinated against $\mathrm{HPV}$, although $12.5 \%$ planned to get vaccinated in the next 12 months. A significant proportion (44.5\%) were undecided. A total of $557(34.3 \%)$ nurses turned down HPV vaccination. The most commonly cited reasons for declining included inadequate information $(49.4 \%)$, the belief that the vaccine was unproven $(23.5 \%)$ and being the wrong age $(25.5 \%)$. Tay's findings [36] suggest that a professional background did not necessarily affect individuals' perceptions of HPV vaccination as these determine their own health choices.

\section{Limitations}

We used the questions extracted by previous researchers in the HPV studies [20,29] but these questions had not been validated. There is a potential risk that some of these questions might not accurately measure of what we aimed to measure. Thus, results emerged from this study might not be generalized to similar replicated studies across countries.

\section{Conclusions}

It is evident that Hong Kong's physicians and nurses have a very low acceptability towards HPV vaccination themselves, and that their general knowledge of HPV vaccination is barely adequate. Physicians and nurses play a pivotal role in shaping public views of HPV vaccination and correcting any misconceptions the public may have. These clinicians are often portrayed as proactive role models in infectious disease control and in preventing outbreaks in the community. The success of HPV prevention and control relies on concerted effort from stakeholders, policymakers, primary-secondary-tertiary care physicians and nurses. It is thus crucial for primary care providers to refresh their knowledge of HPV and to educate their patients about the importance of HPV vaccination in any clinical encounter.

Author Contributions: Conceptualization, J.Y.S.H.; methodology, J.Y.S.H. and T.C..; formal analysis, T.C.; investigation, T.C., P.M. and J.W.; data curation, C.K.S., R.T.H.C.; writing-original draft preparation, T.C.; writing-P.M., J.Z.W. and J.T.F.L.; supervision, J.Y.S.H.; project administration, J.H.; All authors contributed equally to this manuscript.

Funding: This research received no external funding.

Acknowledgments: The authors would like to thank all the physicians and nurses who participated in this study.

Conflicts of Interest: The authors declare no conflict of interest.

\section{References}

1. National Cancer Institute. HPV and Cancer. Available online: http://www.cancer.gov/cancertopics/factsheet/ Risk/HPV (accessed on 19 May 2012).

2. Schiffman, M.; Castle, P.E.; Jeronimo, J.; Rodriguez, A.C.; Wacholder, S. Human papillomavirus and cervical cancer. Lancet 2007, 370, 890-907. 
3. Giuliano, A.R.; Palefsky, J.M.; Goldstone, S.; Moreira, E.D.; Penny, M.E.; Aranda, C.; Vardas, E.; Moi, H.; Jessen, H.; Hillman, R.; et al. Efficacy of Quadrivalent HPV Vaccine against HPV Infection and Disease in Males. N. Engl. J. Med. 2011, 364, 401-411. [CrossRef]

4. Centre for Protection Department of Health, Hong Kong Special Administrative Region. Cervical Cancer. Available online: https:/www.chp.gov.hk/en/healthtopics/content/25/56.html (accessed on 3 March 2019).

5. Department of Health, Hong Kong SAR, Hong Kong. Statistics: Cervical Screening Coverage. Available online: https://www.chp.gov.hk/en/healthtopics/content/25/56.html (accessed on 3 March 2019).

6. Loke, A.Y.; Kwan, M.L.; Wong, Y.-T.; Wong, A.K.Y. The Uptake of Human Papillomavirus Vaccination and Its Associated Factors Among Adolescents: A Systematic Review. J. Prim. Care Community Health 2017, 8, 349-362.

7. Wang, Z.; Wang, J.; Fang, Y.; Gross, D.L.; Wong, M.C.S.; Wong, E.L.Y.; Lau, J.T.F. Parental acceptability of HPV vaccination for boys and girls aged 9-13 years in China-A population-based study. Vaccine 2018, 36, 2657-2665.

8. Yuen, W.W.Y.; Lee, A.; Chan, P.; Tran, L.; Sayko, E. Uptake of human papillomavirus (HPV) vaccination in Hong Kong: Facilitators and barriers among adolescent girls and their parents. PLoS ONE 2018, 13, e0194159.

9. Wang, L.D.L.; Lam, W.W.T.; Wu, J.; Fielding, R. Psychosocial determinants of Chinese parental HPV vaccination intention for adolescent girls: Preventing cervical cancer. Psycho-Oncol. 2015, 24, 1233-1240.

10. Lau, J.; Wang, Z.; Kim, J.; Lau, M.; Lai, C.; Mo, P. Acceptability of HPV Vaccines and Associations with Perceptions Related to HPV and HPV Vaccines Among Men Who Have Sex with Men in Hong Kong. PLoS ONE 2013, 8, e57204.

11. Lee, P.W.H.; Kwan, T.T.C.; Tam, K.F.; Chan, K.K.L.; Young, P.M.C.; Lo, S.S.T.; Cheung, A.N.Y.; Ngan, H.Y.S. Beliefs about cervical cancer and human papillomavirus (HPV) and acceptability of HPV vaccination among Chinese women in Hong Kong. Prev. Med. 2007, 45, 130-134.

12. Wang, L.D.-L.; Lam, W.W.T.; Fielding, R. Determinants of human papillomavirus vaccination uptake among adolescent girls: A theory-based longitudinal study among Hong Kong Chinese parents. Prev. Med. 2017, 102, 24-30.

13. Kepka, D.L.; Coronado, G.; Rodriguez, H.; Thompson, B. Development of a radionovela to promote HPV vaccine awareness and knowledge among Lation parents. Public Health Rep. 2012, 127, 130-138.

14. Lindley, M.C.; Jeyarajah, J.; Yankey, D.; Curtis, C.R.; Markowitz, L.E.; Stokley, S. Comparing human papillomavirus vaccine knowledge and intentions among parents of boys and girls. Hum. Vaccines Immunother. 2016, 12, 1519-1527.

15. Gerend, M.A.; Shepherd, M.A.; Shepherd, J.E. The Multidimensional Nature of Perceived Barriers: Global Versus Practical Barriers to HPV Vaccination. Health Psychol. 2013, 32, 361-369.

16. Perkins, R.B.; Tipton, H.; Shu, E.; Marquez, C.; Belizaire, M.; Porter, C.; Clark, J.A.; Pierre-Joseph, N. Attitudes Toward HPV Vaccination Among Low-Income and Minority Parents of Sons: A Qualitative Analysis. Clin. Pediatr. 2013, 52, 231-240.

17. Siu, J.Y.-M. Perceptions of and barriers to vaccinating daughters against Human Papillomavirus (HPV) among mothers in Hong Kong. Acta Vet. Scand. 2014, 14, 73.

18. Wong, Y. Facilitators and barriers to the acceptance of human papillomavirus (HPV) vaccination among adolescent girls: A comparison between mothers and their adolescent daughters in Hong Kong. BMC Res. Notes 2017, 10, 390.

19. Choi, H.C.W.; Leung, G.M.; Woo, P.P.S.; Jit, M.; Wu, J.T. Acceptability and uptake of female adolescent HPV vaccination in Hong Kong: A survey of mothers and adolescents. Vaccine 2013, 32, 78-84.

20. Cheung, T.; Lau, J.T.F.; Wang, J.Z.; Mo, P.K.H.; Ho, Y.S. Acceptability of HPV vaccines and associations with perceptions related to HPV and HPV vaccines among male baccalaureate students in Hong Kong. PLoS ONE 2018, 13, e0198615.

21. Blumenthal, J.; Frey, M.K.; Worley, M.J.; Tchabo, N.E.; Soren, K.; Slomovitz, B.M. Adolescent Understanding and Acceptance of the HPV Vaccination in an Underserved Population in New York City. J. Oncol. 2012, 2012. [CrossRef]

22. Kwan, T.T.C.; Chan, K.K.L.; Yip, A.M.W.; Tam, K.F.; Cheung, A.N.Y.; Young, P.M.C.; Lee, P.W.H.; Ngan, H.Y.S. Barriers and facilitators to human papillomavirus vaccination among Chinese adolescent girls in Hong Kong: A qualitative-quantitative study. Sex. Transm. Infect. 2008, 84, 227-232.

23. Lee, A.; Ho, M.; Cheung, C.K.M.; Keung, V.M.W. Factors influencing adolescent girls' decision in initiation for human papillomavirus vaccination: A cross-sectional study in Hong Kong. BMC Public Health 2014, 14, 925.

24. Kahn, J.A.; Zimet, G.D.; Bernstein, D.I.; Riedesel, J.M.; Lan, D.; Huang, B.; Rosenthal, S.L. Pediatricians' intention to administer human papillomavirus vaccine: The role of practice characteristics, knowledge, and attitudes. J. Adolesc. Health 2005, 37, 502-510. 
25. De Carvalho, N.S.; Teixeira, L.M.; Pradel, E.M.; Gabardo, J.; Joly, C.; Urbanetz, A.A. Vaccinating against HPV: Physicians' and medical students' point of view. Vaccine 2009, 27, 2637-2640.

26. Lee, Y.Y.; Wang, Z. Facilitators and barriers for healthcare providers to recommend HPV vaccination to attendees of public sexually transmitted diseases clinics in Hong Kong, China. PLoS ONE 2019, 14, e0209942.

27. Sundstrom, B.; Carr, L.A.; Demaria, A.L.; Korte, J.E.; Modesitt, S.C.; Pierce, J.Y. Protecting the Next Generation: Elaborating the Health Belief Model to Increase HPV Vaccination Among College-Age Women. Soc. Mark. Q. 2015, 21, 173-188.

28. Mehta, P.; Sharma, M.; Lee, R.C. Designing and Evaluating a Health Belief Model-Based Intervention to Increase Intent of HPV Vaccination among College Males. Int. Q. Community Health Educ. 2014, 34, 101-117.

29. Mortensen, G.L. Drivers and barriers to acceptance of human-papillomavirus vaccination among young women: A qualitative and quantitative study. BMC Public Health 2010, 10, 68.

30. Black, L.L.; Zimet, G.D.; Short, M.B.; Sturm, L.; Rosenthal, S.L. Literature review of human papillomavirus vaccine acceptability among women over 26 years. Vaccine 2009, 27, 1668-1673.

31. Poole, D.; Tracy, J.; Levitz, L.; Rochas, M.; Sangare, K.; Yekta, S.; Tounkara, K.; Aboubacar, B.; Koita, O.; Lurie, M.; et al. A Cross-Sectional Study to Assess HPV Knowledge and HPV Vaccine Acceptability in Mali. PLOS ONE 2013, 8, e56402.

32. LaMontagne, D.S.; Barge, S.; Le, N.T.; Mugisha, E.; Penny, M.E.; Gandhi, S.; Janmohamed, A.; Kumakech, E.; Mosqueira, N.R.; Nguyen, N.Q.; et al. Human papillomavirus vaccine delivery strategies that achieved high coverage in low- and middle-income countries. Bull. World Health Organ. 2011, 89, 821-830.

33. Chow, S.-N.; Soon, R.; Park, J.S.; Pancharoen, C.; Qiao, Y.L.; Basu, P.; Ngan, H.Y.S. Knowledge, attitudes, and communication around human papillomavirus (HPV) vaccination amongst urban Asian mothers and physicians. Vaccine 2010, 28, 3809-3817.

34. Oh, J.-K.; Lim, M.K.; Yun, E.H.; Lee, E.-H.; Shin, H.-R. Awareness of and attitude towards human papillomavirus infection and vaccination for cervical cancer prevention among adult males and females in Korea: A nationwide interview survey. Vaccine 2010, 28, 1854-1860.

35. Gilkey, M.B.; Moss, J.L.; Coyne-Beasley, T.; Hall, M.E.; Shah, P.D.; Brewer, N.T. Physician communication about adolescent vaccination: How is human papillomavirus vaccine different? Prev. Med. 2015, 77, 181-185.

36. Tay, K.; Tay, S.K.; Tesalona, K.C.; Rashid, N.M.R.; Tai, E.Y.S.; Najib, S.J.M. Factors affecting the uptake of cervical cancer screening among nurses in Singapore. Int. J. Gynecol. Obstet. 2015, 130, 230-234. 